\title{
Right atrial lipoma: the significance of multimodality imaging
}

\author{
Patrycja Molek1, Małgorzata Urbańczyk-Zawadzka², Małgorzata Mielnik², Barbara Szlosarczyk1,3, Jadwiga Nessler 1,4, \\ Andrzej Gackowski' ${ }^{1,4}$
}

\author{
'Department of Coronary Disease and Heart Failure, John Paul II Hospital, Kraków, Poland \\ 2Department of Radiology and Diagnostic Imaging, John Paul II Hospital, Kraków, Poland \\ ${ }^{3}$ Noninvasive Cardiovascular Laboratory, John Paul II Hospital, Kraków, Poland \\ ${ }^{4}$ Institute of Cardiology, Jagiellonian University Medical College, Kraków, Poland
}

\section{Correspondence to: Andrzej Gackowski, $\mathrm{MD}, \mathrm{PhD}$, \\ Department of Coronary Disease and Heart Failure, \\ Noninvasive Cardiovascular Laboratory, \\ John Paul II Hospital, \\ Prądnicka 80, 31-202 \\ Kraków, Poland, \\ phone: +48 126142218 \\ e-mail: \\ agackowski@gmail.com \\ Copyright by the \\ Author(s), 2021 \\ Kardiol Pol. 2021; \\ 79 (7-8): 893-894: \\ DOI: 10.33963/KP.a2021.0024 \\ Received: \\ April 5, 2021 \\ Revision accepted: \\ May 29, 2021 \\ Published online: June 1, 2021}

A 67-year-old woman with a history of mild dyspnea and cough was referred for computed tomography (CT) of the chest. The study did not reveal lung pathology, however, a mass in the right atrial wall was discovered. As the CT scan was optimized for a lung scan, the mass was visualized with motion artifacts. She was referred to the hospital for further evaluation. On admission, the patient did not report any symptoms, including the benign ones present before. Physical examination and ECG did not reveal any abnormalities. No arrhythmia was documented.

Transthoracic echocardiography revealed a normal left ventricular ejection fraction, mild tricuspid regurgitation without annular dilatation, and mild aortic stenosis. Transthoracic echocardiography confirmed the initial CT findings of an immobile mass with a moderate-to-high echogenicity (size $27 \times 15 \mathrm{~mm}$ ) attached to the right atrial roof (Figure 1A). Transesophageal echocardiography showed a heterogeneous, relatively bright mass (size $30 \times 30 \mathrm{~mm}$ ), with a well-defined border, located in the right atrium between the ostia of the inferior and superior caval veins (Figure 1B). A low-velocity scale color Doppler study did not reveal blood flow in the tumor. A wide peduncle and stable attachment to the atrial wall, as well as a relatively solid echostructure of the mass, indicated a different etiology than myxoma. The high echogenicity and a well-defined border suggested a lipoma or fibroma. However, its polycyclic structure could also have indicated a teratoma, and other tumor types were possible. A multi-chamber cardiac cyst containing a dense material was also considered. The vena cava inferior lumen was free of any mass, which would be typical of renal cell carcinoma.

Cardiac magnetic resonance imaging showed a solitary, well-circumscribed, irregular and immobile mass (size $30 \times 20 \times 30 \mathrm{~mm}$ ), arising from the right atrial wall. T1-weighted and fast spin-echo images revealed a high signal of the tumor in a 4-chamber (Figure 1C) and short-axis view (Figure 1D), which was saturated in T1-weighted and fast spin echo with a fat suppression sequence (Figure 1F). The short-tau inversion recovery sequence revealed a very low signal in the mass (Figure 1E); features which indicated a lipid origin of the mass.

Taking into account the absence of symptoms and the high likelihood of a benign tumor, the Heart Team decided on conservative treatment and periodic clinical observation.

Cardiac lipomas are rare, benign non-myxomatous neoplasms of the heart, typically composed of mature fat cells [1], which account for $8.4 \%$ of primary tumors of the heart and pericardium [2]. Most frequently they occur in the right atrium or the left ventricle and they are well-encapsulated, broad-based, immobile tumors. Lipomas should be differentiated with other tumors, particularly myxomas, that are most commonly located in the LA, usually pedunculated, attached to the central part of the interatrial septum in the area of the fossa ovalis [3]. There is no recommendation for surgical treatment, unless they cause arrhythmias, embolization, compression of the coronary arteries, or flow obstruction within the heart [4]. However, cardiac lipomas, unlike myxomas, are more stable and rarely cause pulmonary or peripheral embolization [5]. 


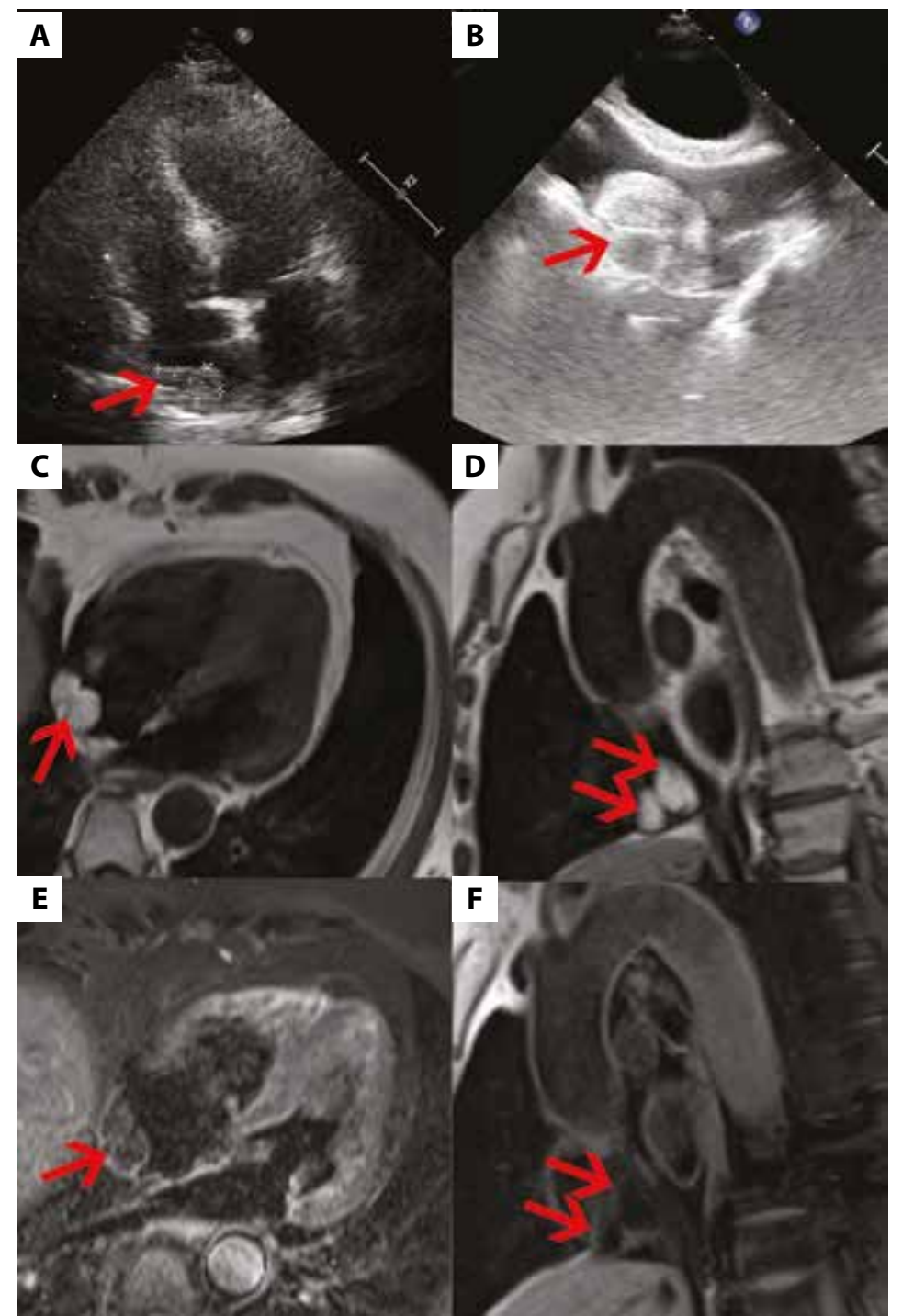

Figure 1. Cardiac lipoma (arrows), visualized using A. Transthoracic echocardiography. B. Transesophageal echocardiography - bicaval view. C. and D. Four chamber and short axis T1-weighted fast spin-echo. E. Cardiac magnetic resonance including four-chamber short-tau inversion recovery imaging. F. Four chamber view T1-weighted with a fat suppression sequence
Our report highlights the importance of a comprehensive tumor evaluation, including echocardiographic assessment of location, shape, echogenicity, presence of microcirculation, and, most importantly, the evaluation of hemodynamic consequences. Tomographic techniques provide an important insight into the tissue composition of the mass. In our case, cardiac magnetic resonance was the most useful, helping to differentiate the tumor, and informing the decision to provide conservative treatment and further follow-up.

\section{Article information}

Conflict of interest: None declared.

Open access: This article is available in open access under Creative Common Attribution-Non-Commercial-No Derivatives 4.0 International (CC BY-NC-ND 4.0) license, allowing to download articles and share them with others as long as they credit the authors and the publisher, but without permission to change them in any way or use them commercially. For commercial use, please contact the journal office at kardiologiapolska@ ptkardio.pl.

How to cite: Molek P, Urbańczyk-Zawadzka M, Mielnik $\mathrm{M}$, et al. Right atrial lipoma: the significance of multimodality imaging. Kardiol Pol. 2021; 79(7-8): 893-894, doi: 10.33963/KP.a2021.0024.

\section{REFERENCES}

1. Durak D, Eren B. Pericardial lipoma: an autopsy case and review of the literature. J Forensic Sci. 2007; 52(4): 949-950, doi: 10.1111/j.1556-4029.2007.00460.x, indexed in Pubmed: 17524057.

2. Li D, Wang W, Zhu Z, et al. Cardiac lipoma in the interventricular septum: a case report. J Cardiothorac Surg. 2015; 10: 69, doi: 10.1186/s13019-015-0275-0, indexed in Pubmed: 25957090.

3. Kurnicka K, Wróbel K, Zygier M, et al. A valvular or atrial tumor? Echocardiography and successful treatment in a patient with an abnormal cardiac mass. Kardiol Pol. 2020; 78(5): 463-464, doi: 10.33963/KP.15209, indexed in Pubmed: 32096777.

4. Castillo JG, Silvay G. Characterization and management of cardiac tumors. Semin Cardiothorac Vasc Anesth. 2010; 14(1):6-20, doi: 10.1177/1089253210362596, indexed in Pubmed: 20472615.

5. Silverman NA. Primary cardiac tumors. Ann Surg. 1980; 191(2): 127-138, doi: 10.1097/00000658-19800200000001, indexed in Pubmed: 7362282. 